\title{
ANALISA DAMPAK BUNYI YANG DIHASILKAN OLEH BANDAR UDARA (BANDARA) SULTAN SYARIF KASIM II (SSK II) TERHADAP AMBANG PENDENGARAN SISWI SMK NEGERI PERTANIAN TERPADU PEKANBARU
}

\author{
Reka Wahyuni, Sri Fitria Retnowaty dan Yulia Fitri \\ Jurusan Fisika Fakultas MIPA dan Kesehatan Universitas Muhammadiyah Riau \\ Email: reka.aulia90@gmail.com, fitriaretnowaty@yahoo.com,yulia_fitri18@yahoo.com
}

\begin{abstract}
The airport of Sultan Syarif Kasim II Pekanbaru is the only one airport located in Pekanbaru city, Riau province and it is the media of air transportation that operates airplane. Sound intensity of plane could create the noisy that effect to psychological disturbance, physical disturbance and communicative disturbance. According to firmness of the head of ministry LH No.48/MENLH/11/1996 about standard quality of noisy level for environmental activities around school is $55 \mathrm{dBA}$. The objective of this study was to measure sound intensity at state vocational high school integrated agriculture Pekanbaru located at noisy area using Sound level meter digital and in order to find out its effect to the level of students' auditory using Gurputala. On the results of research the intensity of sound obtained each day since Monday to Saturday was on average $69.46 \mathrm{dBA}$ and the higher intensity was $93.1 \mathrm{dBA}$. And the results of inspection using garputala with 10 female students that for Rinne test $100 \%$ normal, but for Weber test $50 \%$ the students faced lateralization on right ear. And then for Schwbach the auditory of female students decreases. Thus, the attention of people and government is needed to overcome this problem, one of the ways is planting many trees at school environment and simple air proof in classroom. To obtain the score of auditory step it needs furthermore study using Audiometry to measure auditory step.
\end{abstract}

Keywords: Sound Intensity, Auditory Step, Rinne Test, Weber Test, Schwabach Test

\section{PENDAHULUAN}

Bandar udara Sultan Syarif Kasim II Pekanbaru merupakan satu-satunya Bandar udara yang terletak di Kota Pekanbaru Propinsi Riau yang merupakan sarana transportasi udara yang mengoperasikan pesawat terbang. Besarnya intensitas bunyi yang dihasilkan dari pesawat terbang dapat menimbulkan kebisingan. Kebisingan adalah suara yang tidak diinginkan karena tidak sesuai dengan konteks ruang dan waktu sehingga dapat menimbulkan gangguan terhadap kenyamanan dan kesehatan manusia [1].

Sumber-sumber kebisingan ada tiga macam yaitu kebisingan impulsif, kontinu dan semikontinu. Kebisingan impulsif adalah kebisingan yang memiliki perubahan intensitas suara melebihi $40 \mathrm{~dB}$ dalam waktu yang sangat cepat dan biasanya mengejutkan pendengaran seperti suara ledakan mercon atau ledakan meriam. Kebisingan kontinu adalah kebisingan yang datang secara terus menerus dan berlangsung dalam waktu yang cukup lama.
Misalnya kebisingan yang datang dari suara mesin yang sedang dijalankan. Kemudian kebisingan semi kontinu (intermittent) adalah kebisingan yang terjadi tidak secara terus menerus atau sesaat dam memiliki banyak sumber. Misalnya kebisingan lalu lintas dan suara pesawat terbang yang melintas [2]. Gangguan yang ditimbulkan dari kebisingan tersebut dapat berupa gangguan psikologis, gangguan fisis dan gangguan komunikasi [3].

SMKN Pertanian Terpadu Pekanbaru merupakan salah satu sekolah yang berada dekat dengan bandara SSK II dan termasuk pada kawasan kebisingan tingkat 2 dengan tingkat kebisingan $75 \mathrm{dBA} \leq 80 \mathrm{dBA}$ berdasarkan Peraturan Menteri Perhubungan No.17/2005 tentang Batas-Batas Kawasan Kebisingan Bandar Udara Sultan Syarif Kasim II Pekanbaru [4]. Sedangkan berdasarkan

Ketetapan Kep Men LH No.48/MENLH 11/1996 tentang baku mutu tingkat kebisingan untuk lingkungan kegiatan pada kawasan sekolah 
adalah 55 dBA, sehingga tidak menimbulkan pengaruh terhadap kesehatan baik itu gangguan kenyamanan, komunikasi dan gangguan pada ambang pendengaran [5].

Tujuan pada penelitian ini adalah mengukur intensitas bunyi di SMK Negeri Pertanian Terpadu Pekanbaru dengan menggunakan Sound Level Meter Digital (SLMD) serta melihat pengaruhnya terhadap tingkat ambang pendengaran siswi menggunakan Garputala.

\section{METODOLOGI PENELITIAN}

Penelitian ini dilakukan di SMK Negeri Pertanian Terpadu Pekanbaru dengan menggunakan alat ukur SLMD dan Garputala. Pengukuran intensitas bunyi diambil dengan satu titik pengamatan yang diambil secara acak dan pembacaan dilakukan 15 menit sekali. Sedangkan pengukuran ambang pendengaran dilakukan dengan tiga tes yaitu tes Rinne, tes Weber dan tes Schwabach. Pengukuran dilakukan terhadap siswi kelas tiga (siswi yang sudah lama berada di Sekolah) dengan jumlah siswi yang diukur 10 orang dari 75 Siswa/Siswi berdasarkan umur yang sama, jenis kelamin yang sama dan fisik yang hampir sama.

Analisa data pada penelitian ini dilakukan secara Deskriptif. Setelah data didapatkan, dilakukan pengolahan dengan melakukan pengelompokan yang ditampilkan dalam bentuk Tabel dan Grafik. Kemudian untuk melihat hubungan intensitas bunyi terhadap ambang pendengaran disesuaikan berdasarkan ketetapan Pemerintah dan Kep Men LH No.48/MENLH 11/1996 tentang Baku Mutu Tingkat Kebisingan Untuk Lingkungan Kegiatan Pada Kawasan Sekolah adalah 55 Dba

\section{HASIL DAN PEMBAHASAN}

\section{a. Intensitas Bunyi}

Dari gambar 1 sampai 2 diatas dapat dilihat, bahwa intensitas bunyi tertinggi dari hari senin hingga sabtu adalah 93.1 dBA pada interval waktu 08:45 Wib, hal ini dikarenakan adanya aktivitas penerbangan pada jam tersebut. Kemudian dapat juga dilihat, tingkat bunyi yang paling terendah adalah $43.9 \mathrm{dBA}$ pada interval waktu 10:30 Wib, karena jam tersebut merupakan jam belajar sekolah sehingga intensitas bunyi yang didapatkan rendah dan pada jam tersebut juga tidak adanya penerbangan. Namun tidak menutupi kemungkinan intensitas bunyi tinggi pada jam tersebut. Rata-rata intensitas bunyi dari aktivitas penerbangan dari hari senin hingga sabtu adalah 83.9 dBA dan aktivitas sekolah 61.1 dBA.

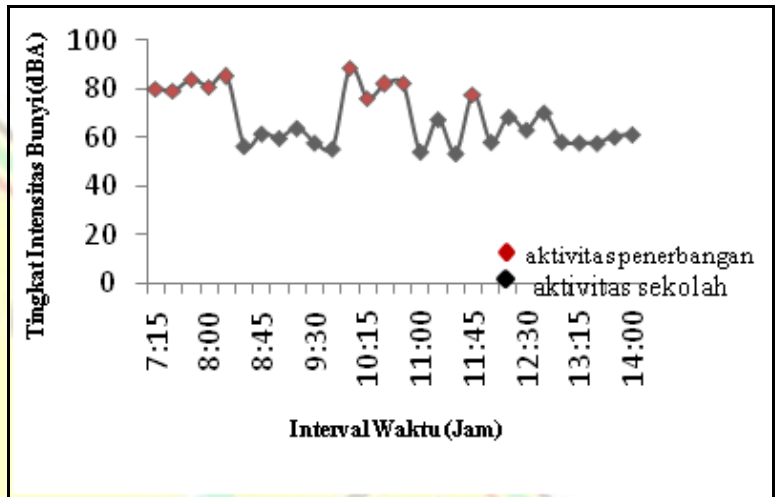

Gambar 1. Tingkat bunyi terhadap waktu pada hari senin tanggal 17 September 2012

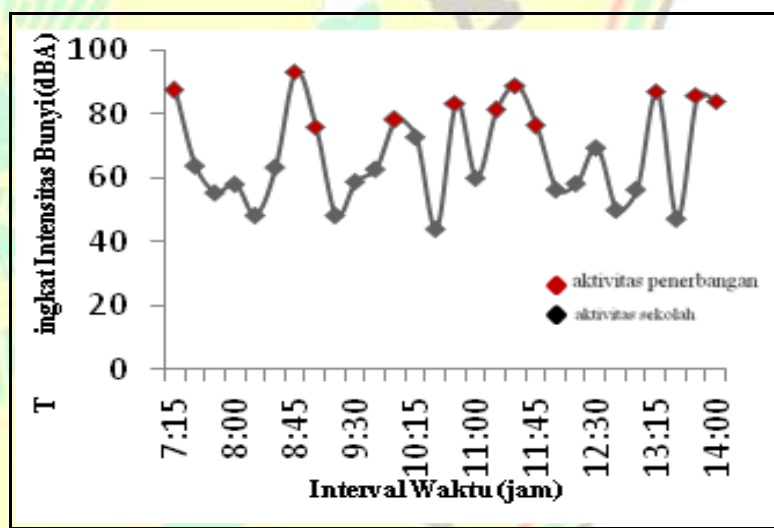

Gambar 2. Tingkat bunyi terhadap waktu pada hari selasa tanggal 18 September 2012

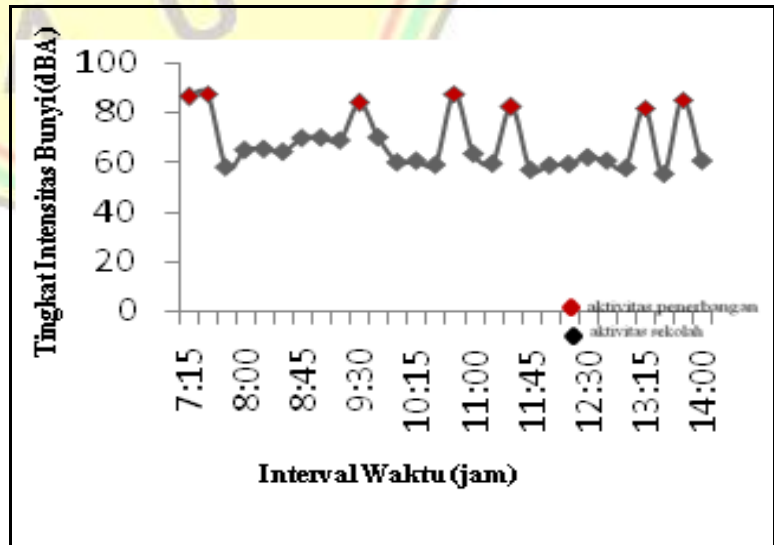

Gambar 3. Tingkat bunyi terhadap waktu pada hari rabu tanggal 19 September 2012 


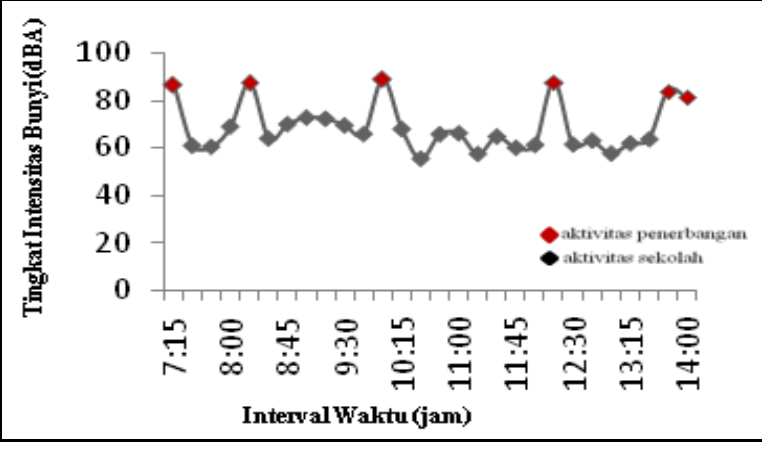

Gambar 5. Tingkat bunyi terhadap waktu pada hari kamis tanggal 20 September 2012

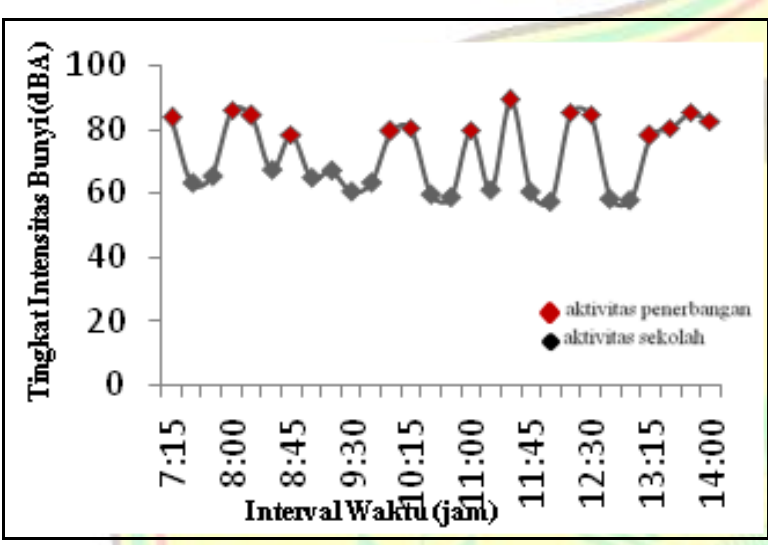

Gambar 6. Tingkat bunyi terhadap waktu pada hari jum'at tanggal 21 September 2012

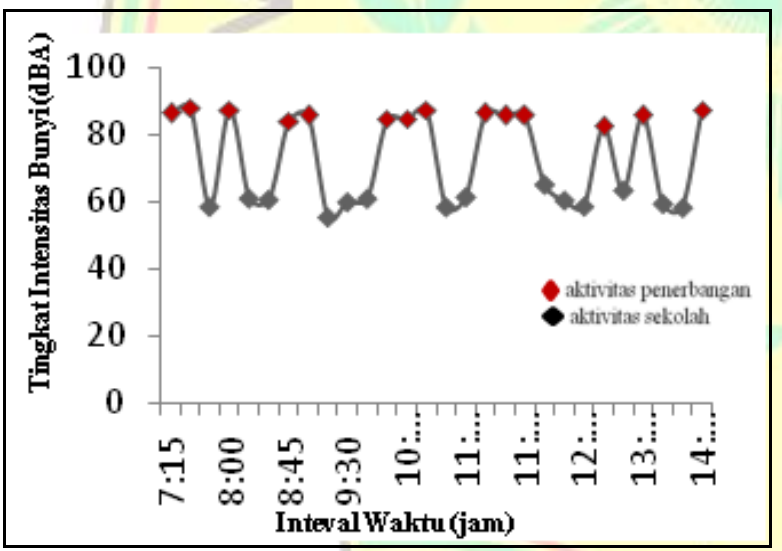

Gambar 7. Tingkat bunyi terhadap waktu pada hari sabtu tanggal 22 September 2012

Tingginya intensitas yang terdapat di sekolah rata-rata dihasilkan dari aktivitas penerbangan Bandara SSK II dan aktivitas Sekolah. Ini dapat dilihat pada grafik Gambar 1 sampai Gambar 7 yaitu hari senin-sabtu, dimana adanya peningkatan intensitas yang tinggi dijam-jam sibuk sekolah serta terdapat penurunan pada jam belajar sekolah. Sedangkan peningkatan yang terjadi dijam-jam tersebut salah satunya disebabkan oleh aktivitas penerbangan Bandara SSK II Pekanbaru.

Berdasarkan ketetapan Kep Men LH No.48/MENLH 11/1996 tentang Baku Mutu Tingkat kebisingan untuk Lingkungan Kegiatan pada kawasan sekolah yaitu $55 \mathrm{dBA}$, maka tingkat intensitas bunyi yang didapatkan pada penelitian ini sudah melebihi dari batas baku mutu tingkat kebisingan yaitu rata-rata intensitas bunyi dari aktivitas penerbangan dari hari senin hingga sabtu adalah 83.9 dBA dan aktivitas sekolah $61.1 \mathrm{dBA}$.

\section{b. Ambang Pendengaran}

Dari Tabel 1. dapat lihat beberapa siswi dicurigai mengalami laterialisasi pada salah satu pendengaran pada tes Weber dan penurunan ambang pendengaran pada tes Schwabach jika dibandingkan hasil antara pemeriksa dan siswi begitu juga sebaliknya. Dimana Pada tes Rinne didapatkan $100 \%$ siswi SMK Negeri Pertanian Terpadu normal, pada tes Weber $50 \%$ siswi dicurigai mengalami Laterialisasi telinga kanan. Terjadinya Laterialisasi pada siswi kemungkinan disebabkan karena pada saat melakukan tes siswi yang diperiksa kurang fokus atau dapat juga disebabkan adanya gangguan pada salah satu telinga siswi. Sedangkan pada tes Schwabach rata-rata siswi SMK Negeri Pertanian Terpadu Pekanbaru kemungkinan mengalami penurunan atau memendeknya ambang pendengarannya yang bisa dilihat pada Tabel 4.1, yaitu ketika siswi diperiksa beberapa siswi sudah tidak mendengar bunyi lagi sedangkan pemeriksa masih mendengar. Hal ini besar kemungkinan disebabkan oleh aktivitas dari Bandara serta aktivitas di Sekolah. Namun tidak menutupi kemungkinan hal ini disebabkan oleh faktor yang lain, seperti faktor keturunan, pernah mengalami gangguan atau benturan/tamparan pada pendengaran dan penggunaan obat-obatan yang berdosis tinggi yang bisa berdampak pada pendengaran serta sebab-sebab lainya. 
Tabel 1. Tes Ambang Pendengaran

\begin{tabular}{|c|c|c|c|c|c|c|c|}
\hline \multirow{2}{*}{ No } & Nama & Tes Riane & \multicolumn{2}{c|}{ Tes Weber } & \multicolumn{2}{c|}{ Tes Schwabach } & \multirow{2}{*}{ Ket } \\
\cline { 3 - 7 } & Siswa & Positif & L. Kanan & Normal & Siswa & Pemeriksa & \\
\hline $\mathbf{1}$ & Siswa 1 & $\checkmark$ & - & $\checkmark$ & $=$ & - & $\checkmark$ (dengar) \\
\hline $\mathbf{2}$ & Siswa 2 & $\checkmark$ & $\checkmark$ & - & - & $\checkmark$ & -(tdk dengar) \\
\hline $\mathbf{3}$ & Siswa 3 & $\checkmark$ & - & $\checkmark$ & $=$ & - & $=$ (sama) \\
\hline $\mathbf{4}$ & Siswa 4 & $\checkmark$ & - & $\checkmark$ & - & $\checkmark$ & \\
\hline $\mathbf{5}$ & Siswa 5 & $\checkmark$ & $\checkmark$ & - & - & $\checkmark$ & \\
\hline $\mathbf{6}$ & Siswa 6 & $\checkmark$ & $\checkmark$ & - & - & $\checkmark$ & \\
\hline $\mathbf{7}$ & Siswa 7 & $\checkmark$ & $\checkmark$ & - & - & $\checkmark$ & \\
\hline $\mathbf{8}$ & Siswa 8 & $\checkmark$ & $\checkmark$ & - & - & $\checkmark$ & \\
\hline $\mathbf{9}$ & Siswa 9 & $\checkmark$ & - & $\checkmark$ & - & $\checkmark$ & \\
\hline $\mathbf{1 0}$ & Siswa 10 & $\checkmark$ & - & $\checkmark$ & $=$ & - & \\
\hline
\end{tabular}

\section{KESIMPULAN DAN SARAN}

\section{Kesimpulan}

Dari hasil penelitian yang dilakukan di SMK Negeri Pertanian Terpadu Pekanbaru dapat diambil kesimpulan sebagai berikut:

1. Hasil pengukuran tingkat bunyi dari hari senin-sabtu rata-rata untuk aktivitas penerbangan adalah $83.9 \mathrm{dBA}$ dan aktivitas sekolah $61.1 \mathrm{dBA}$.

2. Tingginya intensitas bunyi yang terukur dikarenakan SMKN Pertanian Terpadu termasuk pada kawasan kebisingan tingkat 2 dengan nilai tingkat kebisingan $75 \mathrm{dBA} \leq 80$ dBA berdasarkan Peraturan Menteri Perhubungan No.17/2005 tentang BatasBatas Kawasan Kebisingan.

3. Hasil pengukuran ambang pendengaran untuk tes Rinne didapatkan siswi SMK Negeri Pertanian Terpadu Pekanbaru $100 \%$ normal, namun untuk tes Weber $50 \%$ siswi megalami laterialisasi pada salah satu pendengarannya dan untuk tes Schwabach rata-rata siswi mengalami penurunan pada ambang pendengarannya.

4. Terjadinya Laterialisasi dan penurunan pada ambang pendengaran Siswi SMKN Pertanian Terpadu diduga terkait dengan aktivitas penerbangan Bandara SSK II dan aktivitas Sekolah berdasarkan ketetapan Kep Men LH No.48/MENLH No.11/1996 dengan baku mutu untuk kawasan sekolah adalah 55 dBA.

\section{Saran}

Tingkat intensitas bunyi yang didapatkan pada penelitian ini sudah melebihi dari batas ketetapan Kep Men LH No.48/MENLH 11/1996 tentang Baku Mutu Tingkat kebisingan untuk Lingkungan Kegiatan pada kawasan sekolah yaitu $55 \mathrm{dBA}$, dimana rata-rata intensitas bunyi dari aktivitas penerbangan dari hari senin hingga sabtu adalah 83.9 dBA dan aktivitas sekolah 61.1 dBA, sehingga hal ini bisa mengganggu fungsi pendengaran siswa/siswi SMK Negeri Pertanian Terpadu Pekanbaru dan masyarakat yang berada disekitar lingkungan sekolah. Maka perlu dilakukan:

1. Antisipasi terhadap kerusakan pendengaran siswa/siswi SMK Negeri Pertanian Terpadu dan masyarakat yang berada disekitar lingkungannya dengan cara memperbanyak penanaman pohon disekitar sekolah serta dipasang alat kedap suara sederhana diruang belajar, sehingga

2. bunyi yang ditimbulkan tidak langsung diterima oleh telinga.

3. Perlunya perhatian dari pemerintah setempat terkait dengan masalah ini, terutama untuk pembangunan fasilitas Sekolah, Rumah Sakit, Tempat Ibadah dan lain-lain.

4. Untuk mengetahui berapa nilai ambang pendengarnya maka perlu dilakukan pemeriksaan lebih lanjut dengan menggunakan alat ukur Audiometri dan dapat dilakukan untuk peneliti selanjutnya.

\section{DAFTAR PUSTAKA}

Young, Hugh D and Freedman Roger A, 2008. Zemansky and Sears University Physics 12TH Edition With Modern Physics. 
Person Addison Wesley Inc. baston New York

.Sasongko D.P, Hadiyarto A, Sudharto P Hadi, Asmorohadi Nasio, Subagyo A, 2000. Kebisingan Lingkungan. Badan Penerbit Universitas Diponegoro. Semarang.

Ikron, I Made Djaja, Ririn Arminsih Wulandari, 2007. Pengaruh Kebisingan Lalulintas Jalan Terhadap Gangguan Kesehatan Psikologis Anak SDN Cipinang Muara
Kecamatan Jatinegara, Kota Jakarta Timur, Jakarta. Jurnal Makara Kesehatan Vol. 11. NO. 1 Hal. 32-37.

Menteri perhubungan, 2005. Batas-batas kawasan kebisingan Bandar udara sultan syarif kasim II. Pekanbaru. [22 Mei 2012].

Kementrian LH, 2004. Analisis Dampak Lingkungan. Gadjah Mada University Press, Yogyakarta. [20 Mei 2012].

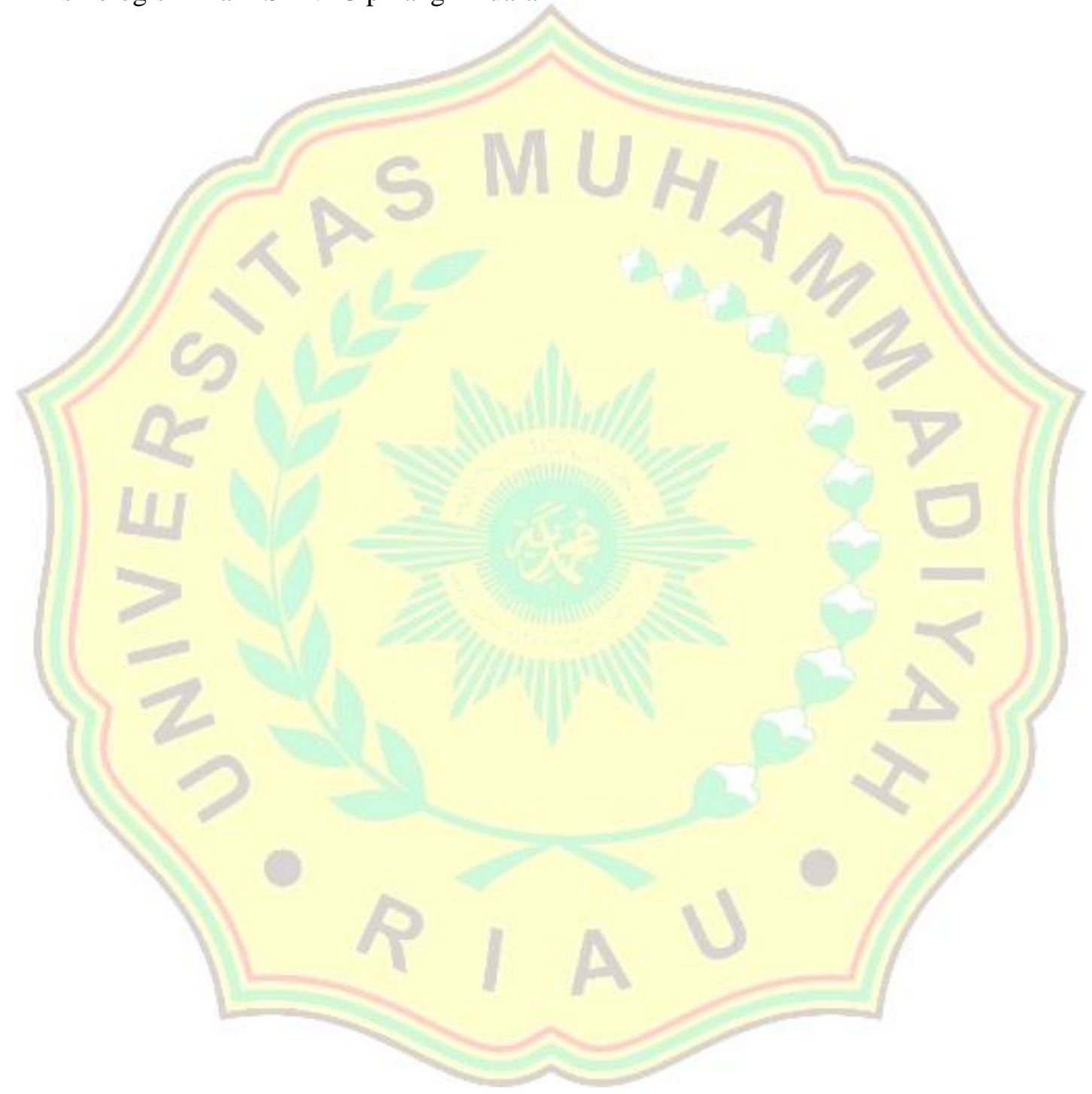

